\title{
Production of $\mathrm{TiB}_{2}$ by SHS and HCl Leaching at different Temperatures:
}

Characterization and Investigation of Sintering Behavior by SPS

\author{
Meltem İpekçi ${ }^{1}$, Selçuk Acar ${ }^{2}$, Mustafa Elmadağl1 ${ }^{3}$, Jürgen Hennicke ${ }^{4}$, \\ Özge Balc1 ${ }^{1 *}$, Mehmet Somer ${ }^{1}$
}

${ }^{1}$ Koç University, Department of Chemistry, Rumelifeneri Yolu, 34450 Sarıyer, İstanbul, Turkey

${ }^{2}$ Pavezyum Chemicals Inc., Tuzla, İstanbul, Turkey

${ }^{3}$ Roketsan Missiles Industries Inc., Materials \& Ballistic Protection Technologies Division, Elmadağ, 06780 Ankara, Turkey

${ }^{4}$ FCT Systeme GmbH, Frankenblick, Germany

*Corresponding author. E-mail: obalci@ku.edu.tr (Ö. Balc1), Tel: +90 212 3382580, Fax: +90 2123381548

\begin{abstract}
Sub-micron sized $\mathrm{TiB}_{2}$ ceramic powders were prepared via self-propagating high-temperature synthesis (SHS) followed by $\mathrm{HCl}$ leaching at different temperatures. Purified powders obtained using optimum process parameters were consolidated by field assisted sintering technology / spark plasma sintering (FAST/SPS) technique. Phase and microstructural analyses of both the powder and sintered samples were carried out by X-ray diffractometer (XRD) and scanning electron microscope (SEM). The chemical analyses and particle size measurements of the specimen were conducted by inductively coupled plasma-mass spectrometry (ICP-MS) and dynamic light scattering (DLS) techniques. The final properties of the sintered sample were determined in terms of density and microhardness. The effects of different $\mathrm{HCl}$ leaching temperatures on the formation, microstructure, particle size, purity and sintering behavior of the SHS-produced $\mathrm{TiB}_{2}$ powders were investigated. The SHS reaction of $\mathrm{TiO}_{2}-\mathrm{B}_{2} \mathrm{O}_{3}-\mathrm{Mg}$ powders as a starting mixture yielded $\mathrm{MgO}, \mathrm{Mg}_{3}\left(\mathrm{BO}_{3}\right)_{2}$ and $\mathrm{Mg}$ beside the desired phase $\mathrm{TiB}_{2}$. All three magnesium containing by-products were completely removed by performing hot $\mathrm{HCl}$ leaching. $\mathrm{TiB}_{2}$ powders after SHS reaction and leaching with $9.3 \mathrm{M} \mathrm{HCl}$ for 30 min at $80^{\circ} \mathrm{C}$ revealed a minimum purity of $98.4 \%$ and a homogenous particle size distribution with an average particle size of $536 \mathrm{~nm}$. In the ultimate SPS experiment which was conducted at $1500^{\circ} \mathrm{C}$ for 5 min under a pressure of $50 \mathrm{MPa}$, a relative density of $94.9 \%$ and a micro-hardness value of $24.56 \mathrm{GPa}$ were achieved.
\end{abstract}


Keywords: A. Powders: solid-state reaction; A. Sintering; B. Microstructure-final; D. Borides.

\section{Introduction}

Titanium diboride $\left(\mathrm{TiB}_{2}\right)$ is one of the technically most important advanced ceramics having high melting point, high strength, low density, high wear, corrosion and thermal shock resistance, excellent chemical stability, outstanding thermal and electrical conductivity [1-3]. According to the phase diagram of Ti-B binary system, $\mathrm{TiB}_{2}$ is the most stable compound with a melting temperature of $3225^{\circ} \mathrm{C}$ [4]. Its extreme hardness arises from the presence of covalent $\mathrm{B}-\mathrm{B}$ bonds and strong Ti-B interactions in the $\mathrm{AlB}_{2}$ type of crystal structure [3-4]. Due to its superior mechanical, physical and chemical properties, $\mathrm{TiB}_{2}$ is used as high temperature evaporation boats, ballistic armors, cutting tools, nuclear rods, wear resistant coatings, cathodes for electro-chemical processing of aluminum, grain refiner in aluminum castings, high temperature sleeves and reinforcement agents in ceramic or metal matrix composites [3, 5-8].

Many processes are available for the fabrication of $\mathrm{TiB}_{2}$ ceramic powders such as high temperature methods using solid state reactions, borothermal and carbothermal reductions, fused-salt electrolysis, solvothermal reactions, gas phase combustion synthesis, chemical vapor deposition, ball milling and mechanochemical synthesis [1-2, 7-15]. However, most of these processes are not suitable for production in industrial quantities either due to the low yield and high cost of the reactants or requirement of expensive equipment [7]. Currently, titanium diboride is commercially accessible via carbothermal reduction of $\mathrm{TiO}_{2}$ and boron oxide at temperatures between $1600-2100^{\circ} \mathrm{C}$ under $\mathrm{Ar}$ atmosphere [9]. The application of high temperatures, long reaction times and the use of complicated equipment are main restrictions for an efficient and simple fabrication of $\mathrm{TiB}_{2}$ powders with high-purity and low particle size $[1,7]$. Self-propagating high-temperature synthesis (SHS) or volume combustion synthesis (VCS) have been designated as alternative energy-saving methods which can be applied to the large scale production of many compounds [5, 16-21]. Compared to carbothermal technique, SHS has different advantages such as less energy loss, high efficiency, simple processing and equipment, and no need for extra processes to obtain finer product to be able to sinter easily [16-17]. During SHS, a highly exothermic combustion reaction occurs which is initiated by an electrical/chemical calorific device or a torch and the reaction becomes self-sustaining by utilizing the thermal energy released from the combustion reaction [19-20]. SHS technique has been reported in current literature as an economical and a novel route for the preparation of $\mathrm{TiB}_{2}$ and $\mathrm{TiB}_{2}$-based ceramic powders [5, 16-23]: The typical combustion synthesis system is $\mathrm{TiO}_{2}-\mathrm{B}_{2} \mathrm{O}_{3}-\mathrm{Mg}$, where the chemical reaction processes affect the resultant phases [19-20]. The 
effects of combustion process parameters such as compositions, particle size and shapes of the reactant mixtures or type and amounts of the diluent additives $(\mathrm{KCl}, \mathrm{NaCl}$ etc.) on the synthesis of $\mathrm{TiB}_{2}$ have been extensively investigated [5, 20-21]. Furthermore, the leaching procedure of the SHS samples was particularly discussed to eliminate by-products; however, there is still a lack of knowledge on determination of the reliable leaching parameters to obtain high-purity $\mathrm{TiB}_{2}$ powders in the literature [22-23].

The sinterability of $\mathrm{TiB}_{2}$, which is the key issue for its technical application, is limited due to its covalent bonding, high melting temperature and low self-diffusion rate $[3,6]$. Therefore, hot pressing (HP), hot isostatic pressing (HIP) or spark plasma sintering (SPS) techniques have been utilized to consolidate $\mathrm{TiB}_{2}$ powders [24-29]. Some sintering aids such as $\mathrm{Ni}$ and $\mathrm{Fe}$ have been employed to improve the sintering behavior [30]. It has been also reported that purity and particle size play a crucial role during sintering and for obtaining high-dense final products [17, 27-29, 31]. Further studies revealed higher densification rates for the nano-crystalline $\mathrm{TiB}_{2}$ powders prepared by the SHS technique compared to those from commercial powders [17, 24]. On the other hand, reports concerning the sintering of combustion synthesized $\mathrm{TiB}_{2}$ ceramics using SPS technique are very limited [17].

In present study, sub-micron and high-purity $\mathrm{TiB}_{2}$ ceramic powders were fabricated via SHS followed by $\mathrm{HCl}$ leaching at different temperatures. The sintering behavior of the powders obtained using optimum process parameters were investigated by SPS technique.

\section{Experimental procedure}

\subsection{Powder processing}

In this study, $\mathrm{TiO}_{2}$ (Sigma Aldrich, > $99 \%$ purity), $\mathrm{B}_{2} \mathrm{O}_{3}$ (Eti Maden, > $98 \%$ purity) and $\mathrm{Mg}$ (Sigma Aldrich, > $99 \%$ purity) powders were used as starting materials. Approximately $50 \mathrm{~g}$ of the powder mixtures containing stoichiometric amounts of the reactants were prepared according to the reaction given in Eq.(1). The mixtures of $\mathrm{TiO}_{2}$ and $\mathrm{B}_{2} \mathrm{O}_{3}$ powders were mechanically mixed for $30 \mathrm{~min}$ by using a rolling mill. Then, $\mathrm{Mg}$ was added to the mixture and distributed homogenously by using a Turbula blender.

$$
\mathrm{TiO}_{2}+\mathrm{B}_{2} \mathrm{O}_{3}+5 \mathrm{Mg} \rightarrow \mathrm{TiB}_{2}+5 \mathrm{MgO}
$$

The SHS experiments were conducted in a very simple, self-constructed low-priced combustion system (i.e. a steel reactor placed in a water-cooled tank). The schematic representation of the SHS arrangement is shown in Figure 1. The as-prepared powder mixtures (Figure 1(h)) were loaded into a steel crucible (Figure 1(g)) which in turn was placed in the steel reactor (Figure 
1(f)). After closing the reactor, Ar gas was loaded into the system (Figure 1(a)) with a flow rate of $10 \mathrm{l} / \mathrm{min}$. Within 5 minutes, the air was replaced by the inert gas and the mixture was ignited by a Hydrogen torch (Figure 1(c)). The use of Ar during the SHS experiments is a must in order to prevent oxidation. Since the mixture of $\mathrm{Mg}$ and $\mathrm{TiO}_{2}$ is a typical thermite, a very exothermic combustion reaction takes place propagating on its own and terminated in a very short time period of approximately 15 seconds. The cooling time by means of the water-cooled tank is comparatively longer lasting 45 - $60 \mathrm{~min}$. The room temperature and hot $\mathrm{HCl}$ leaching processes were applied on the products in order to remove the undesired by-products $\mathrm{MgO}, \mathrm{Mg}_{3}\left[\mathrm{BO}_{3}\right]_{2}$ and metallic $\mathrm{Mg}$. Leaching was carried out in a $9.3 \mathrm{M} \mathrm{HCl}$ solution for $30 \mathrm{~min}$ at room temperature, 70 and $80^{\circ} \mathrm{C}$.

\subsection{Sintering}

Purified powders obtained using optimum process parameters were consolidated by using a field assisted sintering technology / spark plasma sintering (FAST/SPS) system type HP D 25 (FCT Systeme GmbH, Germany). Powders were loaded in a graphite die with an inner diameter of $40 \mathrm{~mm}$. After evacuation and application of an uniaxial pressure of $50 \mathrm{MPa}$, the powder compact was heated to $1500^{\circ} \mathrm{C}$ with a heating rate of $50 \mathrm{~K} / \mathrm{min}$. After a dwell time of $5 \mathrm{~min}$, the pressure was released followed by natural cooling.

\subsection{Characterization}

Phase analyses of the powders and sintered samples were carried out using a Bruker D2 Phaser powder diffractometer with $\mathrm{CuK} \alpha$ radiation in the $2 \Theta$ range of $20-90^{\circ}$ at a step size of $0.02^{\circ}$ and at a rate of $2 \% \mathrm{~min}$. Microstructural characterizations of the powders and sintered products were performed by using a Zeiss EVO LS15 Scanning Electron Microscope (SEM) coupled with an energy dispersive X-Ray spectrometer (EDS). The chemical analysis and particle size measurement of the powders were conducted by using an Agilent 7700x inductively coupled plasma-mass spectrometry (ICP-MS) and a Malvern ZS Zetasizer dynamic light scattering (DLS) techniques, respectively. The purity (\% wt.) of the obtained powders was based on the calculations obtained from the elemental analysis of $\mathrm{Ti}, \mathrm{B}$ and $\mathrm{Mg}$ by ICP-MS measurement. In order to achieve scratch-free mirror finish for SEM analyses and Vickers microhardness measurements, sintered samples were subjected to a typical metallographic preparation procedure (mounting, grounding and polishing). The SEM analyses of the sintered specimen were carried out after polishing and fracture. The densities were measured in ethanol using the Archimedes method and the results were reported as the arithmetic mean of three different measurements taken from the same sample. Vickers microhardness measurements were 
conducted using a Shimadzu HMV Microhardness Tester under a load of $200 \mathrm{~g}$ for $15 \mathrm{~s}$. Microhardness test results for each sample include the arithmetic mean of twenty successive indentations and standard deviations.

\section{Results and discussion}

\subsection{Phase and microstructural analyses of the powders}

Figure 2 shows the XRD pattern of the $\mathrm{TiO}_{2}-\mathrm{B}_{2} \mathrm{O}_{3}-\mathrm{Mg}$ powders after the SHS reaction. As seen from Figure 2, $\mathrm{TiB}_{2}$ (ICDD Card No: 07-0275), $\mathrm{MgO}$ (ICDD Card No: 45-0946), $\mathrm{Mg}_{3}\left(\mathrm{BO}_{3}\right)_{2}$ (ICDD Card No: 04-008-3201) and Mg (ICDD Card No: 35-0821) phases are observed in the product. This indicates that a reaction took place between the starting materials of $\mathrm{TiO}_{2}, \mathrm{~B}_{2} \mathrm{O}_{3}$ and $\mathrm{Mg}$ resulting in the $\mathrm{TiB}_{2}$ and $\mathrm{MgO}$ as majority phases. Unlike the reaction given in Eq.(1) which yields the $\mathrm{MgO}$ phase as the only by-product, a small amount of $\mathrm{Mg}_{3}\left(\mathrm{BO}_{3}\right)_{2}$ phase formed and unreacted $\mathrm{Mg}$ remained in the microstructure. This is understandable since products of the actual reaction triggered by the SHS reactions which is away from the equilibrium conditions may not completely conform to those of the ideal case. On the other hand, there are no remaining $\mathrm{TiO}_{2}$ and no additional compounds between $\mathrm{Ti}-\mathrm{Mg}$, B-Mg, Ti-Mg-O and Ti-B-O in the detection limit of XRD. The formation of magnesium borate phases arising from the reaction between $\mathrm{MgO}$ and $\mathrm{B}_{2} \mathrm{O}_{3}$ during ignition has already been reported in $\mathrm{SHS}$ of $\mathrm{TiB}_{2}$ powders [18-19, 21-22]. It has been previously suggested that the addition of excess Mg starting powder could reduce the produced magnesium borate phases [20]. In the present case, however, the SHS sample comprises a minor quantity of unreacted Mg (Figure 2). Previous results showed that $\mathrm{Mg}_{2} \mathrm{TiO}_{4}$ phase was also formed by a parallel reaction between unreacted $\mathrm{TiO}_{2}$ and $\mathrm{MgO}$ and remained as the main impurity even after acid leaching [18-19, 21]. Obviously, the complete consumption of $\mathrm{TiO}_{2}$ during ignition process prevented the further formation of the acid resistant Ti-based by-products, such as $\mathrm{Mg}_{2} \mathrm{TiO}_{4}$ [20]. The absence of magnesium titanate phases in Figure 2 is very likely related to powder preparation stage where the starting materials were prepared by mechanical mixing/Turbula blending and a homogenous distribution of the reactants was obtained. Furthermore, the higher homogeneity, reactivity and contact area of powder particles provide a higher combustion temperature and decrease the reaction temperature and combustion speed [20].

The XRD pattern of the SHS sample after $\mathrm{HCl}$ leaching at room temperature is depicted in Figure 3 which shows that the unwanted by-product $\mathrm{MgO}$ was completely removed from the powder mixture after leaching with $9.3 \mathrm{M} \mathrm{HCl}$. The preference of using highly concentrated hydrochloric acid $(9.3 \mathrm{M})$ during leaching process is the considerable temperature increase in 
the solution. Since leaching of $\mathrm{MgO}$ with $\mathrm{HCl}$ is fairly exothermic, increasing the acid concentration will also raise the solution temperature and enhance the dissolution of unwanted phases [22]. As seen from Figure 3, the acid treatment at room temperature is only partially successful, dissolving $\mathrm{MgO}$ exclusively while the impurities $\mathrm{Mg}_{3}\left(\mathrm{BO}_{3}\right)_{2}$ and a small amount of $\mathrm{Mg}$ are still present in the residue. These findings confirm that the utilized leaching parameters are suitable only for the removal of $\mathrm{MgO}$ but not adequate to remove magnesium borate and magnesium phases. Similar observations have also been made in previous studies related with the room temperature acid leaching of SHS products [22]. Therefore, the leaching of the powders was carried out using the same acid concentration and duration (i.e. $9.3 \mathrm{M} \mathrm{HCl}, 30$ min) but at 70 and $80^{\circ} \mathrm{C}$. Figure 4 shows the XRD patterns of the SHS samples after hot $\mathrm{HCl}$ leaching at different temperatures. Figure 4(a) and (b) reveal the effectiveness of hot $\mathrm{HCl}$ treatment for complete dissolution of magnesium borate and magnesium phases, since only $\mathrm{TiB}_{2}$ was detected in both microstructures. The X-ray powder diagram of $\mathrm{TiB}_{2}$ comprises ten peaks at values of $27.603^{\circ}, 34.130^{\circ}, 44.443^{\circ}, 56.994^{\circ}, 61.099^{\circ}, 68.131^{\circ}, 68.316^{\circ}, 71.877^{\circ}$, $78.624^{\circ}$ and $88.394^{\circ}$ which are respectively indexed as (001), (100), (101), (002), (110), (102), (111), (200), (201) and (112) crystal planes (Figure 4(a) and (b)). Furthermore, the peak intensities of $\mathrm{TiB}_{2}$ phase on the XRD pattern increased when the leaching temperature was raised from 70 to $80^{\circ} \mathrm{C}$, which could be as a result of the reduction of the average crystallite size and an increase in lattice strain. The positive effect of hot $\mathrm{HCl}$ leaching on the yield of $\mathrm{TiB}_{2}$ produced by SHS reaction has also been reported according to which pure $\mathrm{TiB}_{2}$ powders were obtained after hot leaching of SHS samples in $5 \mathrm{M} \mathrm{HCl}$ solution at $75^{\circ} \mathrm{C}$ for $15 \mathrm{~h}$ [18].

The SEM images and EDS analysis of the SHS sample after $\mathrm{HCl}$ leaching at room temperature are illustrated in Figure 5. Figure 5(a) and (b) represent irregular agglomerates having sizes in the range of $200 \mathrm{~nm}$ and $2 \mu \mathrm{m}$. The general EDS measurement (Figure 5(c)) taken from the region in Figure 5(b) reveals that the microstructure comprise the elements $\mathrm{Ti}, \mathrm{Mg}, \mathrm{B}$ and $\mathrm{O}$. Due to the absence of $\mathrm{MgO}$ in the XRD pattern in Figure 3, the detection of the elements $\mathrm{Mg}$ and $\mathrm{O}$ in the EDS analysis can only be explained by the presence of magnesium borate and magnesium in the sample. Similarly composed polycrystalline $\mathrm{TiB}_{2}$ powders obtained after acid leaching were also observed and reported in current literature [5].

Figure 6 illustrates the SEM images and EDS analysis of the SHS samples after hot $\mathrm{HCl}$ leaching at different temperatures. As seen from Figure 6(a) and (b), after removal of impurities from $\mathrm{TiB}_{2}$ powders, the blurred microstructure with adherence and agglomeration of the particles (Figure 5(a)-(b)) are disappeared. The SEM images of the hot leached powders (Figure 
6(a) and (b)) contain polygonal, equiaxed and spheroidal-shaped particles ranging in sizes between $400 \mathrm{~nm}$ and $1 \mu \mathrm{m}$. Furthermore, hot leached samples do not consist of perfect spheroidal-shaped particles throughout the structure due to the high adiabatic temperatures and cooling rate of the SHS reaction [5, 22]. It can be seen from Figure 6(b) that specimen treated at $80^{\circ} \mathrm{C}$ consist of distinct particles with relatively clear boundaries which are more homogenous than those leached at room temperature (Figure 5(a)-(b)). The general EDS measurement (Figure 6(c)) taken from the region in Figure 6(b) reveals that the samples are composed of only $\mathrm{Ti}$ and $\mathrm{B}$, which is in good agreement with the result of the XRD analysis from the hot leached powders in Figure 4(b). The related EDS analyses revealed no detectable peaks for $\mathrm{Mg}$ and $\mathrm{O}$ which is a clear proof for the complete removal of all unwanted phases after $\mathrm{HCl}$ leaching at $80^{\circ} \mathrm{C}$.

\subsection{Particle size analyses and purity of the powders}

Figure 7 and Table 1, respectively, present the particle size measurements and the values of average particle size/purity of the SHS samples after $\mathrm{HCl}$ leaching at different temperatures. As it is evident from Figure 7(a) and (b), more homogeneous particle size distribution was obtained for the hot leached powders than those leached at room temperature. This finding harmonizes also well with the SEM images of the leached powders in Figure 5(a) and 6(b) in which an uneven size distribution of the particles was observed. On the other hand, the average particle size of powders leached at room temperature slightly increased from 487 to 645 and $536 \mathrm{~nm}$ after hot leaching at 70 and $80^{\circ} \mathrm{C}$, respectively (Table 1). Agglomerated particles observed in SEM images in Figure 5(a)-(b) and 6(a)-(b) prevents the observation of the smaller ones. Therefore, particle size measurement carried out after homogenization of the powder mixtures gave more accurate results as depicted in Figure 7 and Table 1. It has been reported that the addition of SHS diluents $\left(\mathrm{NaCl}, \mathrm{KCl}, \mathrm{CaCl}_{2}\right)$ to the reaction mixture reduced the grain growth of particles possibly by reducing the adiabatic temperatures and giving a coating on $\mathrm{TiB}_{2}$ particles $[5,17]$. The production of $\mathrm{TiB}_{2}$ powders with an average particle size of around 100 $\mathrm{nm}$ was achieved in literature by adding $\mathrm{NaCl}$ diluent (20-45 wt. \%) to the reaction mixture during SHS reaction $[17,21]$. On the other hand, the sizes of the SHS'ed and leached $\mathrm{TiB}_{2}$ powders produced without adding any SHS diluents were reported as between 9 and $65 \mu \mathrm{m}[5$, 22]. It was also claimed that the effect of initial size and green density of the starting particles was more pronounced than the effect of the addition of SHS diluents [21]. Thus, in the present study, leached $\mathrm{TiB}_{2}$ particles in average sizes lower than $650 \mathrm{~nm}$ were achieved without using any SHS diluents. This is most likely due to the initial powder preparation step which provided 
a high homogeneity, reactivity and contact area of powder particles [20]. Furthermore, high acid concentration and utilized temperatures during leaching process may provide $\mathrm{TiB}_{2}$ structures in the absence of any impurity resulting smaller network grains having high surface areas [22].

The purity $(\%)$ of $\mathrm{TiB}_{2}$ powders was calculated based on the $\mathrm{Ti}: \mathrm{B}$ ratio obtained from the elemental analysis by ICP-MS. The results are presented in Table 1 confirming that the purity of the $\mathrm{TiB}_{2}$ powders produced after $\mathrm{HCl}$ leaching at room temperature is considerably increased from 90 to $96.5 \%$ for those leached at $70^{\circ} \mathrm{C}$. The highest purity (>98.4\%) was achieved for SHS'ed $\mathrm{TiB}_{2}$ samples obtained after $\mathrm{HCl}$ treatment at $80^{\circ} \mathrm{C}$. Chemical analyses of the $\mathrm{HCl}$ leached samples at different temperatures are compatible to their XRD and SEM/EDS analyses given in Figure 3, 4, 5(c) and 6(c). On the basis of these results, the optimal leaching conditions for the production of high-purity (> $98.4 \%$ ) and sub-micron scale $(536 \mathrm{~nm})$ SHS'ed $\mathrm{TiB}_{2}$ powders with homogeneous particle size distribution were determined to be in $9.3 \mathrm{M} \mathrm{HCl}$ solution for $30 \mathrm{~min}$ at $80^{\circ} \mathrm{C}$. These powders obtained using optimum process parameters will be further named as optimized powders.

\subsection{Phase and microstructural analyses of the sintered product}

Optimized powders were consolidated by SPS technique at $1500^{\circ} \mathrm{C}$ for $5 \mathrm{~min}$ under a pressure of $50 \mathrm{MPa}$. In order to determine the probable contaminations or phase formations occurred during SPS, sintered samples were subjected to XRD analyses which confirm that the specimen are free of any detectable contamination, secondary or other undesired phases. The XRD pattern of the spark plasma sintered sample originated from optimized powders is presented in Figure 8 which shows that the obtained sample contains solely mono-phase $\mathrm{TiB}_{2}$. In contrast to the present findings, there are two similar studies reporting on the formation of secondary TiB phase after SPS of $\mathrm{TiB}_{2}$ powders and the negative effect of $\mathrm{TiB}$ on the microstructural and mechanical properties of the sintered products $[29,32]$.

The SEM images of the spark plasma sintered sample originated from optimized powders taken from their polished and fractured surfaces are given in Figure 9. Figure 9(a) illustrates that SPS of pure $\mathrm{TiB}_{2}$ powders provides a fine microstructure without any observable pore and segregation in the SEM image. In addition, the fracture surface in Figure 9(b) indicates a nearly complete densification of the sample. This shows the effectiveness of SPS technique even at relatively low temperature $\left(1500^{\circ} \mathrm{C}\right)$ due to factors, such as the application of pressure and the presence of pulsed direct electric current through powders [29, 33]. The applied high electric current provides a local increase in the temperature at the particle contacts which significantly 
enhances the diffusivity of the powders and accelerates the densification [29, 33]. Similar SPS conditions $\left(1500^{\circ} \mathrm{C}\right.$ for $15 \mathrm{~min}$ under pressure of $\left.60 \mathrm{MPa}\right)$ were employed for the consolidation of mechanochemically synthesized niobium boride powders; however, a complete densification could not be obtained [34]. This is most likely due to the phase transformation occurred during SPS after which unstable and secondary phases of niobium borides were formed [34]. Thus, the phase stability during the SPS of metal boride powders may be the key factor for high densification rates [34]. Non-porous microstructures of the polished and fractured sample (Figure 9(a) and (b)) promote the effect of the obtained phases (Figure 8) during SPS on the densification of $\mathrm{TiB}_{2}$ powders. Furthermore, a closer look at the fractured surface of the sample in Figure 9(c) shows that there is no aggregates along the grain boundaries and triple point corners by means of the absence of any secondary phase in the microstructure. In a related study, it was reported that the TiB clusters occurred during SPS of $\mathrm{TiB}_{2}$ powders were pulled out during the fracture process indicating the weak bonding between the matrix $\left(\mathrm{TiB}_{2}\right)$ and secondary phase (TiB) [32]. Figure 9(b) and (c) also reveal that the grain sizes of spark plasma sintered SHS'ed $\mathrm{TiB}_{2}$ vary between $500 \mathrm{~nm}$ and $5 \mu \mathrm{m}$. This non-uniform size of grains throughout the microstructure of fracture surface could result from the partial formation of big platelets during sintering which might occur due to the high defect concentrations in SHS samples [17].

\subsection{Density and microhardness measurements of the sintered product}

Table 2 presents the density, relative density and microhardness values of the spark plasma sintered sample originated from optimized powders. Relative density (\%) of the sintered sample was calculated by taking into account the theoretical density of $\mathrm{TiB}_{2}$ and the measured Archimedes density of spark plasma sintered $\mathrm{TiB}_{2}$ powders. As seen from Table 2, sintered product exhibits a relative density of $94.9 \%$ and a microhardness value of $24.56 \mathrm{GPa}$. The high relative density value of $94.9 \%$ conform well to the non-porous microstructures presented in the SEM images (Figure 9(a)-(c)). The considerably high density and microhardness values (Table 2) are attributed to the high purity (Table 1) and homogenous particle size distribution (Figure 7(b)) of the optimized powders. It is well known that the impurities in the microstructure of the precursor powders prevent the complete densification during SPS process. The results confirm that high-purity and homogeneous size distribution of precursor $\mathrm{TiB}_{2}$ particles play a crucial role in consolidation process, microstructure and hardness of the resultant samples. They further give evidence of the essential effect of acid leaching process on the SHS'ed $\mathrm{TiB}_{2}$ powders for obtaining the desired powder properties with enhanced sintering behavior. 
A comparative pressureless sintering study of $\mathrm{TiB}_{2}$ powders revealed that SHS-produced powders showed $97 \%$ densification at $1950^{\circ} \mathrm{C}$, whereas the identically sintered commercial powder could only be densified to $86 \%$ at the same temperature [17]. Sintered micron-scale $\mathrm{TiB}_{2}$ powders exhibited a relative density of $96.1 \%$ and a microhardness of $18.3 \mathrm{GPa}$ by SPS at $1500^{\circ} \mathrm{C}$ for $10 \mathrm{~min}$ under a pressure of $40 \mathrm{MPa}$ [32]. A similar study also reported on the SPS of micron-scale $\mathrm{TiB}_{2}$ powders according to which a relative density of $79.44 \%$ and a microhardness of $17.46 \mathrm{GPa}$ were achieved at $1780^{\circ} \mathrm{C}$ under a pressure of $50 \mathrm{MPa}$ [28]. On the other hand, higher microhardness values $(\sim 26 \mathrm{GPa})$ of the sintered $\mathrm{TiB}_{2}$ products with high relative density $(>92 \%)$ were obtained by hot pressing at temperatures above $1800^{\circ} \mathrm{C}$ with long holding times (> 2 h) $[6,27]$. Thus, comparing the reported density and hardness values of $\mathrm{TiB}_{2}$ ceramics with those of the present study, it can be stated that the achieved relative density $(94.9 \%)$ and microhardness values (24.56 GPa) are remarkably high for the utilized consolidation processes and parameters (SPS at $1500^{\circ} \mathrm{C}$ for 5 min under a pressure of $50 \mathrm{MPa}$ ).

\section{Conclusions}

In this study, sub-micron sized $\mathrm{TiB}_{2}$ ceramic powders in high purity were successfully synthesized from stoichiometric $\mathrm{TiO}_{2}-\mathrm{B}_{2} \mathrm{O}_{3}-\mathrm{Mg}$ powder mixtures by $\mathrm{SHS}$ and subsequent $\mathrm{HCl}$ leaching at different temperatures. The consolidation of the optimized powders was performed by SPS technique. The results were discussed regarding the effect of different leaching temperatures on the formation, microstructure, particle size, purity and sintering behavior of the SHS-produced $\mathrm{TiB}_{2}$ powders. They allow following conclusions:

- The SHS reaction of $\mathrm{TiO}_{2}-\mathrm{B}_{2} \mathrm{O}_{3}-\mathrm{Mg}$ powder mixtures yielded $\mathrm{TiB}_{2}$ and $\mathrm{MgO}$, as main phases while $\mathrm{Mg}_{3}\left(\mathrm{BO}_{3}\right)_{2}$ and $\mathrm{Mg}$ formed as by-products. The unwanted $\mathrm{MgO}$ could be completely removed after leaching with $9.3 \mathrm{M} \mathrm{HCl}$ at room temperature, leaving $\mathrm{Mg}_{3}\left(\mathrm{BO}_{3}\right)_{2}$ and also very small amount of $\mathrm{Mg}$ in the residual powder. High-purity $\mathrm{TiB}_{2}$ powders without any impurities were obtained after hot $\mathrm{HCl}$ leaching at 70 and $80^{\circ} \mathrm{C}$.

- Pure $\mathrm{TiB}_{2}$ powders -i.e. without detectable foreign phases in XRD patterns- with a minimum purity of $98.4 \%$, an average particle size of $536 \mathrm{~nm}$ and a homogenous particle size distribution were obtained after SHS and hot leaching in $9.3 \mathrm{M} \mathrm{HCl}$ for 30 $\min$ at $80^{\circ} \mathrm{C}$.

- After SPS at $1500^{\circ} \mathrm{C}$ for 5 min under a pressure of $50 \mathrm{MPa}, \mathrm{TiB}_{2}$ was the only observable phase in the microstructure of the sintered product originated from optimized powders. 
Polished and fractured surfaces of the spark plasma sintered sample showed nearly full densification.

- $\mathrm{TiB}_{2}$ ceramics having a relative density of $94.9 \%$ and a microhardness value of 24.56 GPa were obtained by FAST/SPS of $\mathrm{TiB}_{2}$ powders prepared by SHS and hot $\mathrm{HCl}$ leaching at $80^{\circ} \mathrm{C}$. The remarkably high density and hardness values are related to the purification degree and homogenous particle size distribution of the powders achieved at optimum process conditions.

\section{Acknowledgements}

The authors would like to thank Roketsan A.Ş. for the generous financial support. The authors also would like to thank Koç University Surface Science and Technology Center (KUYTAM) for instrumental support and characterization of samples.

\section{References}

[1] F. Habashi, Handbook of Extractive Metallurgy, Wiley-VCH, Heidelberg, Germany, 1997.

[2] A.W. Weimer, Carbide, Nitride and Boride Materials Synthesis and Processing, Chapman \& Hall, London, United Kingdom, 1997.

[3] R.G. Munro, Material properties of titanium diboride, J. Res. Natl. Inst. Stan. 105 (2000) 709-720.

[4] J. L. Murray, P. K. Liao, K. E. Spear, The B-Ti (Boron-Titanium) system, Bulletin of Alloy Phase Diagrams, 7 (1986) 550-555.

[5] A.K. Khanra, L.C. Pathak S.K. Mishra, M.M. Godkhindi, Effect of $\mathrm{NaCl}$ on the synthesis of $\mathrm{TiB}_{2}$ powder by a self-propagating high-temperature synthesis technique, Mater. Lett. 58 (2004) $733-738$.

[6] C. Subramanian, T.S.R.C. Murthy, A.K. Suri, Synthesis and consolidation of titanium diboride, Int. J. Refract. Metals Hard Mater. 25 (2007) 345-350.

[7] V.I. Matkovich, Boron and refractory borides, Springer-Verlag New York, 1977.

[8] V. Sundaram, K.V. Logan, R.F. Speyer, Reaction path in the magnesium thermite reaction to synthesize titanium diboride, J. Mater. Res. 12 (1997) 2657-2664.

[9] R.V. Krishnarao, J. Subrahmanyam, Studies on the formation of $\mathrm{TiB}_{2}$ through carbothermal reduction of $\mathrm{TiO}_{2}$ and $\mathrm{B}_{2} \mathrm{O}_{3}$, Mater. Sci. Eng. A. 362 (2003) 145-151. 
[10] V.V. Ivanov, I.A. Blokhina, S.D. Kirik, Synthesis of $\mathrm{TiB}_{2}$ by carbothermal reduction of oxides at lowered temperatures, Russ. J. Appl. Chem. 86 (2013) 1650-1655.

[11]S.H. Kang, D.J. Kim, Synthesis of nano-titanium diboride powders by carbothermal reduction, J. Eur. Ceram. Soc. 27 (2007) 715-718.

[12] R. Ricceri, P. Matteazzi, A fast and low-cost room temperature process for $\mathrm{TiB}_{2}$ formation by mechanosynthesis, Mater. Sci. Eng. A. 379 (2004) 341-346.

[13] J.W. Kim, J. Shim, J. Ahn, Y.W. Cho, J. Kim, K.H. Oh, Mechanochemical synthesis and characterization of $\mathrm{TiB}_{2}$ and $\mathrm{VB}_{2}$ nanopowders, Mater. Lett. 62 (2008) 2461-2464.

[14] L. Shi, Y. Gu, L. Chen, Z. Yang, J. Ma, Y. Qian, A convenient solid-state reaction route to nanocrystalline $\mathrm{TiB}_{2}$, Inorg. Chem. Commun. 7 (2004) 192-194.

[15] Y. Gu, Y. Qian, L. Chen, F. Zhou, A Mild Solvothermal Route to Nanocrystalline Titanium Diboride, J. Alloys Compd. 352 (2003) 325-327.

[16]D.D. Radev, M. Marinov, Properties of titanium and zirconium diborides obtained by selfpropagated high-temperature synthesis, J. Alloys Compd. 244 (1996) 48-51.

[17] A.K. Khanra, M.M. Godkhindi, Comparative studies on sintering behavior of selfpropagating high-temperature synthesized ultra-fine titanium diboride powder, J. Am. Ceram. Soc. 88 (2005) 1619-1621.

[18]E. Bilgi, H.E. Çamurlu, B. Akgün, Y. Topkaya, N. Sevinç, Formation of $\mathrm{TiB}_{2}$ by volume combustion and mechanochemical process, Mater. Res. Bull. 43 (2008) 873-881.

[19]H. Zarrinpour, S. Firoozi, V. Milani, Ignition and chemical mechanisms of volume combustion synthesis of titanium diboride, Ceram. Int. 42 (2016) 11217-11223.

[20] W. Weimin, F. Zhengyi, W. Hao, Y. Runzhang, Chemistry reaction processes during combustion synthesis of $\mathrm{B}_{2} \mathrm{O}_{3}-\mathrm{TiO}_{2}-\mathrm{Mg}$ system, J. Mater. Process. Technol. 128 (2002) $162-168$.

[21]A. Nekahi, S. Firoozi, Effect of $\mathrm{KCl}, \mathrm{NaCl}$ and $\mathrm{CaCl}_{2}$ mixture on volume combustion synthesis of $\mathrm{TiB}_{2}$ nanoparticles, Mater. Res. Bull. 46 (2011) 1377-1383.

[22]U. Demircan, B. Derin, O. Yücel, Effect of $\mathrm{HCl}$ concentration on $\mathrm{TiB}_{2}$ separation from a self-propagating high-temperature synthesis (SHS) product, Mater. Res. Bull. 42 (2007) $312-318$. 
[23] J.Y. Lok, K.V. Logan, J.J. Payyapilly, Acid leaching of SHS produced magnesium oxide/titanium diboride, J. Am. Ceram. Soc. 92 (2009) 26-31.

[24] M. Ouabdesselam, Z.A. Munir, The sintering of combustion-synthesized titanium diboride, J. Mater. Sci. 22 (1987) 1799-1807.

[25] J. Schmidt, M. Boehling, U. Burkhardt, Y. Grin, Preparation of titanium diboride $\mathrm{TiB}_{2}$ by spark plasma sintering at slow heating rate, Sci. Technol. Adv. Mater. 8 (2007) 376-382.

[26] D. Salamon, M. Eriksson, M. Nygren, Z. Shen, Homogeneous $\mathrm{TiB}_{2}$ ceramics achieved by electric current-assisted self-propagating reaction sintering, J. Am. Ceram. Soc. 90 (2007) 3303-3306.

[27] A. Rabiezadeh, A.M. Hadian, A. Ataie, Synthesis and sintering of $\mathrm{TiB}_{2}$ nanoparticles, Ceram. Int. 40 (2014) 15775-15782.

[28] A. Turan, F.C. Sahin, G. Goller, O. Yucel, Spark plasma sintering of monolithic $\mathrm{TiB}_{2}$ ceramics, Ceram. Process. Res. 15 (2014) 464-468.

[29] N.S. Karthiselva, B.S. Murty, S.R. Bakshi, Low temperature synthesis of dense $\mathrm{TiB}_{2}$ compacts by reaction spark plasma sintering, Int . J. Refract. Met. Hard Mater. 48 (2015) 201-210.

[30] C. Yang, H. Guo, D. Mo, S. Qu, X. Li, W. Zhang, L. Zhang, Bulk TiB 2 -Based Ceramic Composites with Improved Mechanical Property Using $\mathrm{Fe}-\mathrm{Ni}-\mathrm{Ti}-\mathrm{Al}$ as a Sintering Aid, Materials 7 (2014) 7105-7117.

[31]D. Demirskyi, J. Cheng, D. Agrawal, A. Ragulya, Densification and grain growth during microwave sintering of titanium diboride, Scr. Mater. 69 (2013) 610-613.

[32] A. Mukhopadhyay, T. Venkateswaran, B. Basu, Spark plasma sintering may lead to phase instability and inferior mechanical properties: A case study with $\mathrm{TiB}_{2}$, Scr. Mater. 69 (2013) 159-164.

[33]Z.A. Munir, U. Anselmi-Tamburini, M. Ohyanagi, The effect of electric field and pressure on the synthesis and consolidation of materials: a review of the spark plasma sintering method, J. Mater. Sci. 41 (2006) 763-777.

[34] Ö. Balc1, D. Ağaoğulları, F. Muhaffel, M. L. Öveçoğlu, H. Çimenoğlu, İ. Duman, Effect of sintering techniques on the microstructure and mechanical properties of niobium borides, J. Eur. Ceram. Soc. 36 (2016) 3113-3123. 